\title{
Advanced Field Weakening Control for Squirrel-Cage Induction Motor in Wide Range of DC-Link Voltage Conditions
}

\author{
Yung-Deug Son*, Jun-Hyung Jung** and Jang-Mok Kim ${ }^{\dagger}$
}

\begin{abstract}
This paper proposes a field weakening control method for operating an induction motor with a variable DC input voltage condition. In the variable DC voltage condition such as a battery, the field weakening method are required for the maximum output power. The conventional field weakening control methods can be used for operating the induction motor over the rated speed in a constant DC-link voltage condition. However, the conventional methods for operating the motor with the variable DC voltage is not suitable for the maximum output power. To overcome this problem, this paper proposes the optimized field weakening control method to extend the operating range of the induction motor with a rated power in a limited thermal and a wide DC input voltage conditions. The optimized d-axis and q-axis current equations are derived according to the field weakening region I and II to extend the operating region. The experimental results are presented to verify the effectiveness of the proposed method.
\end{abstract}

Keywords: Induction motor, Field weakening region, $\Delta$-connection, Y-connection, $\mathrm{d}$ - and $\mathrm{q}$-axis currents

\section{Introduction}

Recently, the induction motors have been used in various industrial applications with a variable speed drive system such as pump, fan and compressor. The field weakening control methods for the induction motor are applied for operating the motor above a rated speed [1]. For the last few decades, several papers have researched the field weakening control. In [2], this paper presents the optimal rotor flux as a function about the rotor speed for maximum torque in field weakening region. The look-up table can be used to produce the flux despite the need for an excessive memory and the complicated implementation [3]. As a general method, the rotor flux is obtained by an equation which is derived based on the voltage and current limits. These methods have a wide range speed region under the constant DC input voltage condition [4-6]. The comparison of the robust field weakening control methods is presented in [7]. This paper mentioned the performance of the four scheme in terms of the speed response, quality of the current and flux quality. But, the variable DC voltage condition was not analyzed. In [8], the DC voltage utilization is extended to reach the hexagonal trajectory for the field weakening control.

In the induction motor drive applications using battery as DC power source, the field weakening control should be

\footnotetext{
$\dagger$ Corresponding Author: Dept. of Electrical Engineering, Pusan National University, Korea. (jmok@pusan.ac.kr)

* Dept. of Mechanical Facility Control Engineering, Korea University of Technology and Education, Korea. (ydson@koreatech.ac.kr)

** Dept. of Electrical Engineering, Pusan National University, Korea. (jjhyung@pusan.ac.kr)

Received: February 24, 2016 ; Accepted: October 28, 2016
}

applied to operate at rated power because of the wide range DC input voltage characteristic of the battery. Despite the field weakening control, the lack of DC input voltage is not avoidable in some DC input voltage conditions. In this case, using the $\Delta$-connected induction motor could result in good solution [9]. The $\Delta$-connected induction motor can generate a rated power even under a low input voltage. However, the temperature of power device increases due to the high input current. Therefore, the Y-connected induction motor is more suitable and field weakening control should be used for limited DC input voltage and appropriate thermal condition [9].

This paper proposes the field weakening control method considering the limited thermal and DC input voltage conditions. The proposed method is suggested for generating the rated output power using the minimum phase current with a wide DC input voltage range. Hence, a new d-axis and q-axis current equations are presented to operate at the rated power according to the field weakening region I and II. In region I, a new d-axis and q-axis current equations are derived by the voltage limit ellipse and constant torque curve. In region II, the d-axis and q-axis currents are designed to generate the maximum torque in the given DC input voltage condition. The effectiveness of the proposed method is verified by the experimental results.

\section{Analysis of Squirrel-cage Induction Motor Characteristics According to the Wire Connection \\ The input voltage and current characteristics of induction motor are different depending on the stator wire}


Table 1. Specification of target 3-phase induction motor

\begin{tabular}{c|c|c}
\hline Specification & Y-connection & $\Delta$-connection \\
\hline Rated power & \multicolumn{2}{|c}{$5.5[\mathrm{~kW}]$} \\
\hline Rated speed & \multicolumn{2}{|c}{$1160[\mathrm{rpm}]$} \\
\hline Input voltage & $380[\mathrm{Vrms}]$ & $220[\mathrm{Vrms}]$ \\
\hline The minimum required DC voltage & $540[\mathrm{Vdc}]$ & $310[\mathrm{Vdc}]$ \\
\hline Input current & $18.38[\mathrm{Arms}]$ & $31.78[\mathrm{Arms}]$ \\
\hline Conduction loss ratio & 1 & $\sqrt{3}$ \\
\hline Voltage condition & dissatisfactory & satisfactory \\
\hline
\end{tabular}

connection. In case of the Y-connected induction motor, the motor has a high input voltage and a low input current characteristics. In contrast, in case of the $\Delta$-connection, the motor has a low input voltage and a high input current characteristics compared to the Y-connection motor. The specifications of the target induction motor are shown in Table 1.

The inverter loss can be calculated by using the equation of conventional paper and IGBT application note $[10,11]$.

In the $\Delta$-connected motor, the rated output power can be generated in a condition of the DC input voltage of magnitude below $450[\mathrm{Vdc}]$. but the rated IGBT temperature increases continuously up to 100 degrees Celsius without saturation. The maximum operating temperature of IGBT is 150 degree Celsius and available ambient temperature is 70 degrees Celsius [9]. For this reason, the operating the $\Delta$ connected motor with the low DC voltage has a problem of the thermal break of the IGBT when the drive system is operated for a long time. Therefore, the induction motor with the Y-connection is preferred in a condition of the variable DC voltage because it has less input current and losses.

However, the lack of the DC link voltage causes the input voltage shortage in the rated speed and the power condition when the stator is wired as the Y-connection. This is related to the voltage utilization of the pulse-widthmodulation (PWM) method. The rated line to line input voltage of the target induction motor is a $380[\mathrm{Vrms}]$. So, the minimum required DC input voltage has to be more than a 540[Vrms]. If the DC input voltage has less than the minimum required $\mathrm{DC}$ voltage, the rated operation of the motor is impossible due to the input voltage shortage.

According to the experimental result, the actual speed decreases to $1080[\mathrm{rpm}]$ despite the $1160[\mathrm{rpm}]$ reference speed. In this situation, the output power also decreases to $4.49[\mathrm{~kW}]$. This means that about $1[\mathrm{~kW}]$ output power shortage is occurred compared to the $5.5[\mathrm{~kW}]$ rated output power.

\section{Influence of the DC-Link Voltage Drop on Conventional Field Weakening Control [5]}

In field weakening region of induction motor, voltage and current limit should be considered. The output voltage

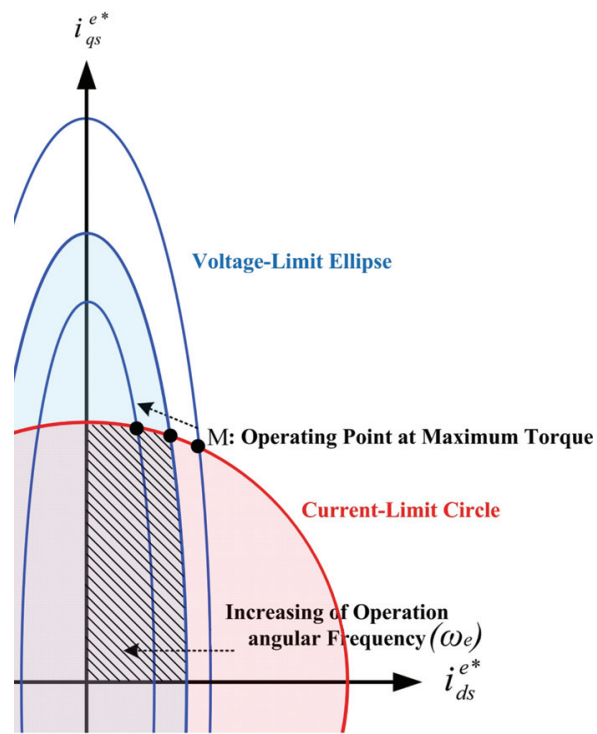

Fig. 1. Maximum torque operating point of field weakening control

of the motor drive system could not be larger than the maximum output voltage determined by the DC voltage. Also the output current cannot exceed than the maximum value that is limited by inverter and machine current rating. Therefore, the $\mathrm{d}-\mathrm{q}$ axis current should satisfy the following equations.

$$
\begin{gathered}
\left(\omega_{e} L_{s} i_{d s}^{e}\right)^{2}+\left(\omega_{e} \sigma L_{s} i_{q s}^{e}\right)^{2} \leq V_{s \max }^{2} \\
i_{d s}^{e 2}+i_{q s}^{e^{2}} \leq I_{s \max }^{2}
\end{gathered}
$$

where, $\omega_{e}$ is the synchronous angular speed and $i_{d s}{ }^{e}, i_{q s}{ }^{e}$ are the d-axis and q-axis component of stator currents in synchronous reference frame and $V_{\text {smax }}, I_{\text {smax }}$ are maximum stator voltage and current, $L_{s}$ is the self-inductance of stator, $\sigma$ is the total leakage factor $\left(=1-L_{m}{ }^{2} / L_{s} L_{r}\right), L_{r}$ and $L_{m}$ are the self-inductance of rotor and the mutual inductance, respectively.

From Eq. (1), the voltage-limit ellipse equation can be derived as follow.

$$
\frac{i_{d s}^{e}{ }^{2}}{\left(V_{s \max } / \omega_{e} L_{s}\right)^{2}}+\frac{i_{q s}^{e}{ }^{2}}{\left(V_{s \max } / \sigma \omega_{e} L_{s}\right)^{2}} \leq 1
$$

The voltage-limit ellipse shrinks when the operating frequency increases as shown in Fig. 1. The available daxis and q-axis currents are inside of the voltage-limit ellipse from Eq. (3). The current-limit circle is not changed by the operating speed.

For operating the motor, the d-axis and q-axis current should be located inside of circle. Therefore, the overlapped region of the current-limit circle and voltage ellipse is used for operating the motor in field weakening region. There are many d-axis and q-axis current com- 
binations in this region. However, the maximum torque under the given condition can be generated on the intersection point of the voltage-limit ellipse and the current-limit circle. The d-axis and q-axis current are decided by the intersection point which can be derived from Eqs. (1) and (2) as shown in Eqs. (4) and (5).

$$
\begin{aligned}
i_{d s}^{e^{*}} & =\sqrt{\frac{\left(\frac{V_{s \max }}{\omega_{e}}\right)^{2}-\left(\sigma L_{s} I_{s \max }\right)^{2}}{L_{s}^{2}-\left(\sigma L_{s}\right)^{2}}} \\
i_{q s}^{e^{*}} & =\sqrt{\frac{\left(L_{s} I_{s \max }\right)^{2}-\left(\frac{V_{s \max }}{\omega_{e}}\right)^{2}}{L_{s}^{2}-\left(\sigma L_{s}\right)^{2}}} \\
& =\sqrt{I_{s \max }{ }^{2}-i_{d s}^{e^{*} 2}}
\end{aligned}
$$

As the rotor speed increases, the slip angular speed also increases as Eqs. (4) and (5). Finally, when the slip angular speed reaches to the maximum angular speed $\left(\omega_{s l-m a x}\right)$, Eqs. (4) and (5) cannot generate the maximum torque under the given condition. Therefore, Eq. (4) divides motor operating point into two regions.

Above the maximum angular speed $\left(\omega_{s l-m a x}\right)$, the maximum torque point of the voltage limit ellipse is included in the current limit circle as shown in Fig. 2. Therefore, $\mathrm{d}-\mathrm{q}$ axis currents of the maximum torque points can be derived from Eq. (1) and the induction motor torque equation is obtained as follow.

$$
T_{e}=\frac{3}{2} \frac{p}{2} \frac{L_{m}^{2}}{L_{r}} i_{d s}^{e} i_{q s}^{e}
$$

where, $p$ is the number of poles.

The result of maximum torque operating point can be represented as follows.

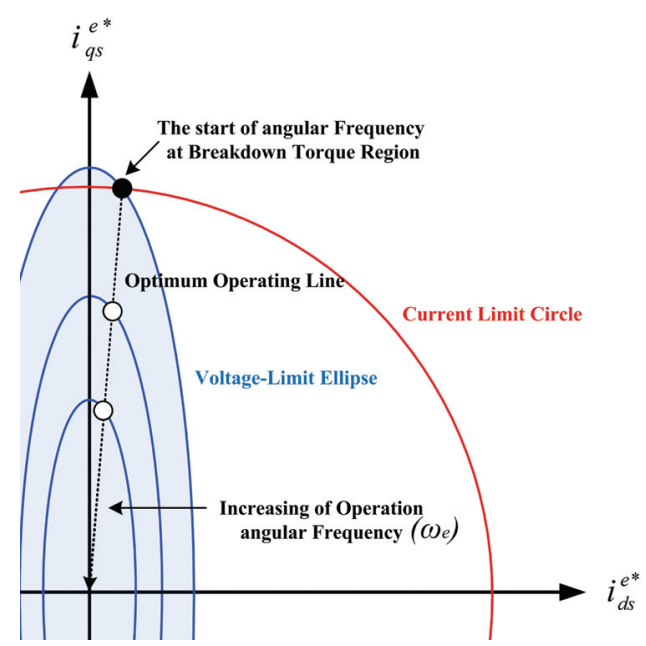

Fig. 2. Maximum torque operation points of above $\omega_{s l-m a x}$

$$
\begin{gathered}
i_{d s}^{e^{*}}=\frac{V_{s \max }}{\sqrt{2} \omega_{e} L_{s}} \\
i_{q s}^{e^{*}}=\frac{V_{s \max }}{\sqrt{2} \omega_{e} \sigma L_{s}}
\end{gathered}
$$

The conventional field weakening algorithm could be a solution in some applications that has a wide DC input voltage. However, it is not applicable if the current limit is not enough as shown in Fig. 3. If the DC voltage is higher than the rated voltage, the induction motor can be operated at the rated speed and torque as shown at point A of Fig. 3 . On the other hand, if the DC voltage is dropped under the required DC voltage, the output power reduction is unavoidable in spite of the field weakening algorithm as shown by point $\mathrm{B}$ because the current and voltage limit are associated with the maximum power. In this case, the increase of the current limit is necessary to operate the motor at the rated power and torque. The increase of the

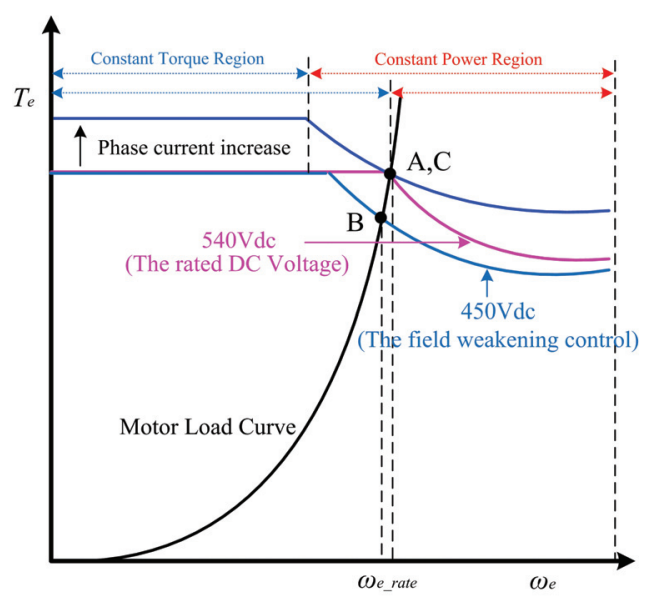

Fig. 3. Torque curve considering the increase of phase current limit value

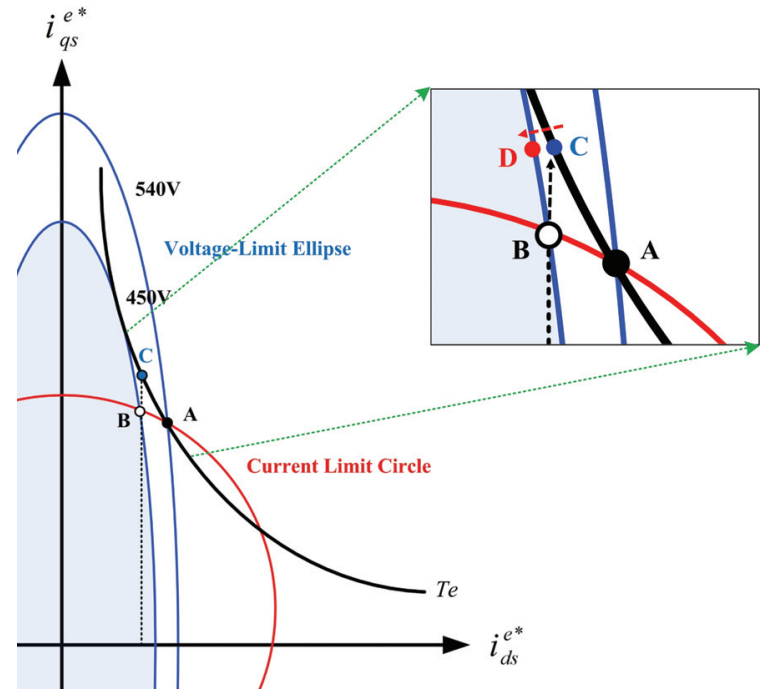

Fig. 4. Operation points of field weakening region I 
current limit leads to increase of the output power. And, it is possible to operate at rated speed and torque despite the DC voltage shortage as shown by operating point $\mathrm{C}$ of Fig. 4.

However, it is also difficult to decide the limit current for generating the rated power in the conventional field weakening algorithm. Especially, when the q-axis current limit only increases, the target operating point is $\mathrm{C}$ in Fig. 4. But, it is impossible to operate at this point due to the voltage limit ellipse. Hence, the operating point moves to D. It means that the current limit needs to increase more. For this reason, sometime conventional method doesn't offer solution for a wide DC input voltage characteristic.

This paper proposes an enhanced field weakening algorithm to solve this problem. Since the maximum input current should be changed instantly to operate the motor at the rated power, the proposed method does not consider the current limit circle.

\section{Proposed Field Weakening Control Algorithm}

For operating the induction motor at the rated power, this paper proposes an enhanced field weakening algorithm. In proposed algorithm, the operating points are divided into two regions. According to the proposed field weakening method for the region I, the d-axis and q-axis currents are decided at the intersection point on the voltage limit ellipse and constant torque curve. And, the torque value is derived from the mechanical equation as follow.

$$
T_{e}=\frac{P_{e}}{\omega_{m}}=\frac{p}{2} \frac{P_{e}}{(1-s) \omega_{e}}
$$

where, $P_{e}$ is the output power, $\omega_{m}$ is the mechanical angular speed, $s$ is the slip.

From Eqs. (3), (6) and (9), the intersection point of daxis and q-axis current at the rated speed can be derived in (10) and (11).

$$
i_{d s}^{e^{*}}=\sqrt{\frac{-B+\sqrt{B^{2}-4 A C}}{2 A}}
$$

where $A=L_{s}^{2}, \quad B=-\frac{V_{s \max }^{2}}{\omega_{e}^{2}}, \quad C=\frac{4 \sigma^{2} L_{s}^{2}(1-s)^{2} \omega_{e}^{2}}{K_{e}^{2} P_{e}^{2} p^{2}}$.

$$
i_{q s}^{e^{*}}=\frac{\sqrt{V_{s \max }^{2}-\left(\omega_{e} L_{s} i_{d s}^{e^{*}}\right)^{2}}}{\omega_{e} \sigma L_{s}}
$$

where, $K_{e}$ is the back-EMF constant of the induction motor.

Fig. 5 shows the voltage limit ellipse and constant torque curve at the rated speed. When the DC input voltage is the rated DC voltage in the rated speed condition, the

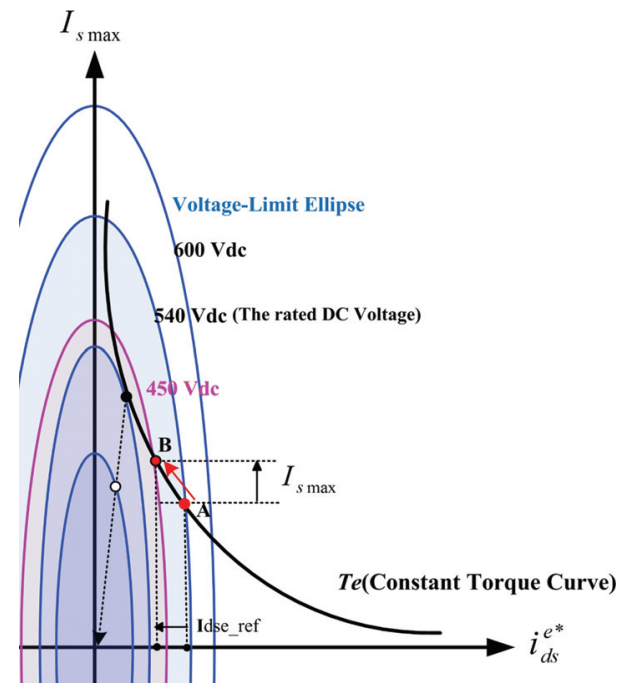

Fig. 5. Constant torque operating point of proposed field weakening

induction motor is operated at the intersection point A. If the DC input voltage is reduced below the rated DC voltage, the operation point moves to the intersection point B. As the speed increases, the d-axis current decreases and q-axis current increases. Also, the phase current increases automatically. It means the current flowing through the motor exceeds the rated current value. Hence, when the proposed method is used to operate the motor in the region I, the temperature of the motor must be monitored. And the system must be stopped if the temperature increases too high. However, if the speed increases further, the intersection point doesn't exist due to the reduced voltage limit ellipse as shown in Fig. 5.

The field weakening region II can be detected from Eq. (12) as follow.

$$
B^{2}-4 A C<0
$$

In region II, Eq. (10) should be a complex variable. So, if Eq. (12) is true, the proposed method for the region II should be applied for operating the motor at maximum power in a given condition. The d-axis and q-axis current in the region II can be obtained as follow. The d-axis and q-axis stator voltage equation can be presented as Eqs. (13) and (14).

$$
\begin{gathered}
V_{d s}^{e^{*}}=R_{s} i_{d s}^{e^{*}}-\omega_{e} \sigma L_{s} i_{q s}^{e^{*}} \\
V_{q s}^{e^{*}}=R_{s} i_{q s}^{e^{*}}+\omega_{e} L_{s} i_{d s}^{e^{*}}
\end{gathered}
$$

where, $V_{d s}{ }^{e^{*}}, V_{q s}{ }^{e^{*}}$ are d-axis and q-axis component of stator voltage references in the synchronous reference frame.

From Eqs. (6), (13) and (14), the d-axis and q-axis currents for operating at maximum power can be derived as (15) and (16). Both equations for $\mathrm{d}-\mathrm{q}$ axis current considers 


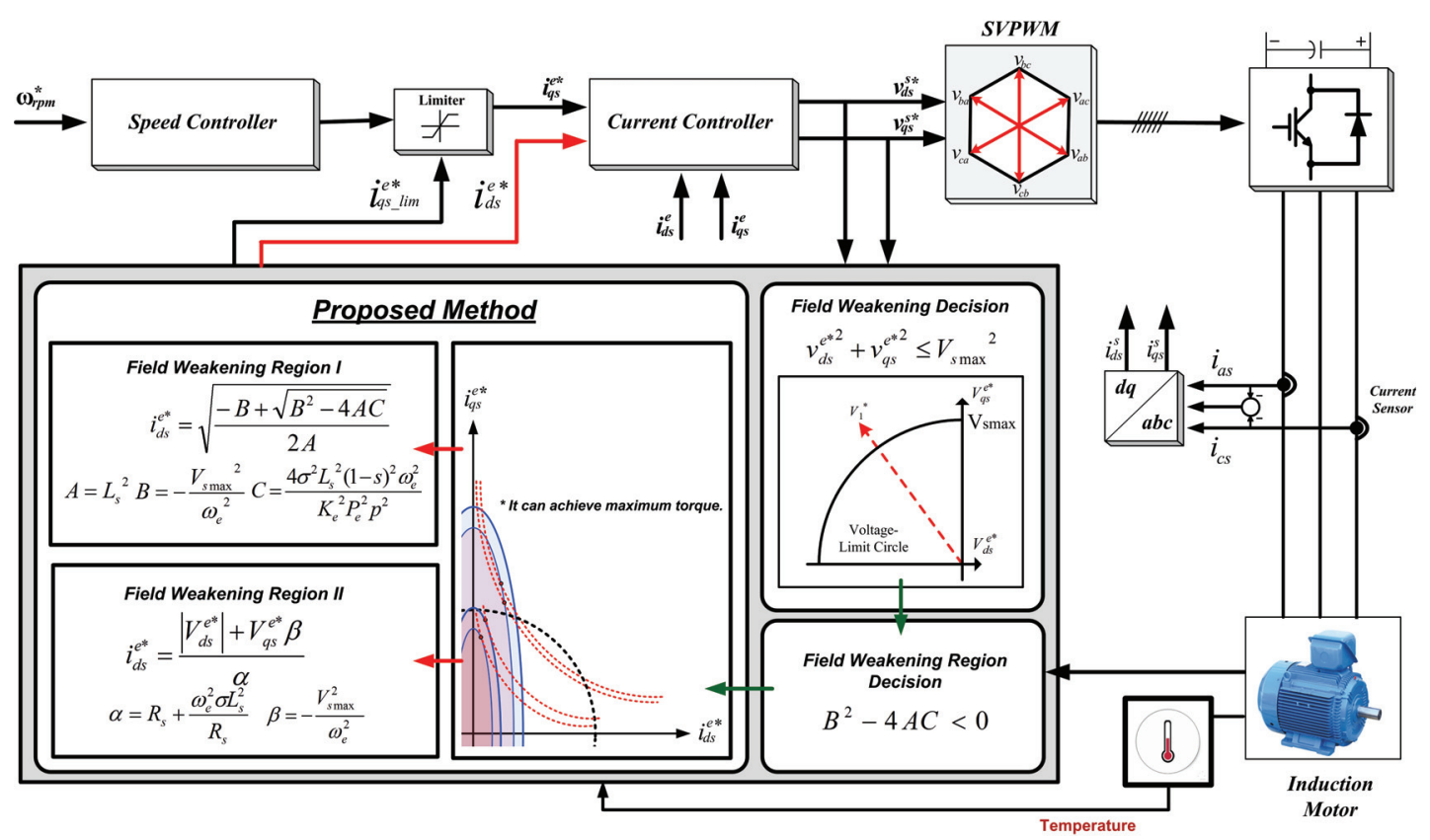

Fig. 6. Block diagram of the proposed field weakening control method for induction motor

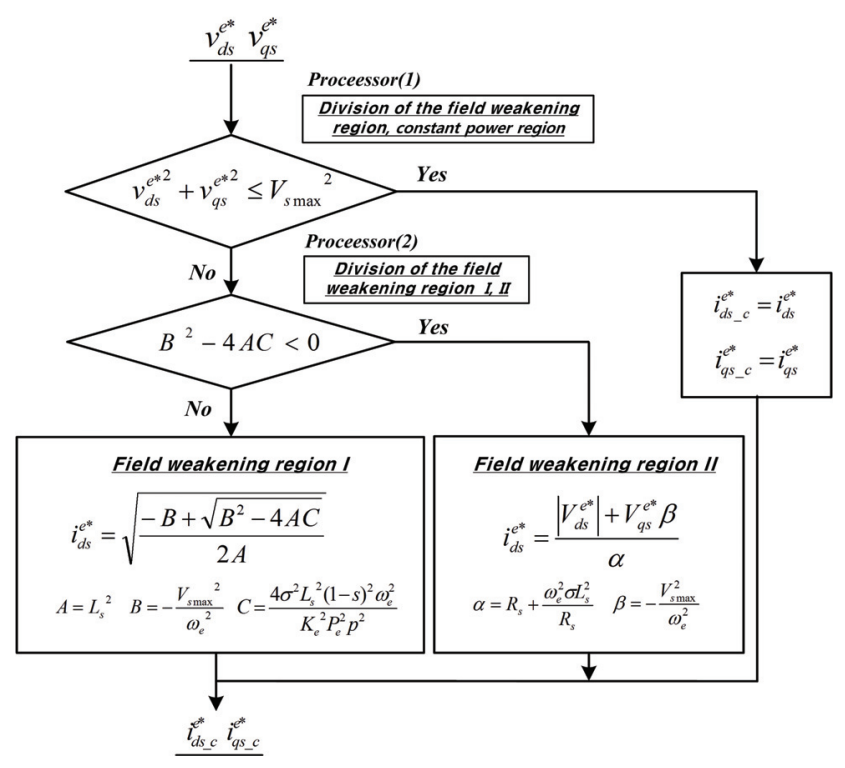

Fig. 7. Flow chart of the proposed field weakening control algorithm

the stator resistance.

$$
\begin{aligned}
& i_{d s}^{e^{*}}=\frac{\left|V_{d s}^{e^{*}}\right|+V_{q s}^{e^{*}} \beta}{\alpha} \\
& i_{q s}^{e^{*}}=\frac{T_{e}}{K_{e} i_{d s}^{e^{*}}}
\end{aligned}
$$

where, $\alpha=R_{s}+\frac{\omega_{e}^{2} \sigma L_{s}^{2}}{R_{s}} \quad \beta=-\frac{V_{s \max }^{2}}{\omega_{e}^{2}}$
Fig. 7 shows the flow chart of the proposed field weakening method for both region I and II.

The amplitude of the phase input voltage and maximum stator input voltage that can be applied at a given DC input voltage will be compared. From the result of this comparison, the operation of the motor will be decided to be in the field weakening region or the constant torque region. Then, the operation of the motor in the field weakening region I and II is determined by Eq. (12) as shown in the flow chart of Fig. 7. If the intersection point exists on the current limit circle and voltage limit ellipse, the motor can be operated in the region I. If not, the field weakening control method for the region II should be used. Fig. 6 shows the entire control block diagram including the proposed method.

\section{Experimental Results}

The experiment was performed using the M-G (MotorGenerator) set as shown in Fig. 8. The induction motor was used for comparing the performance of the proposed field weakening method and the conventional methods. The load torque was applied by using Permanent Magnet Synchronous Motor (PMSM). Two back-to-back converter systems are used for controlling the Induction motor and PMSM. The control interface is based on the DSP TMS320c28346 manufactured by the TI. And the control frequency is $10[\mathrm{kHz}]$. The experimental conditions associated with region I are presented in Table 2.

Fig. 9 shows the experimental result of the conventional method in the region $\mathrm{I}$. When the $\mathrm{DC}$ input voltage decreases from $600[\mathrm{~V}]$ to $450[\mathrm{~V}]$, the rotor speed is reduced 


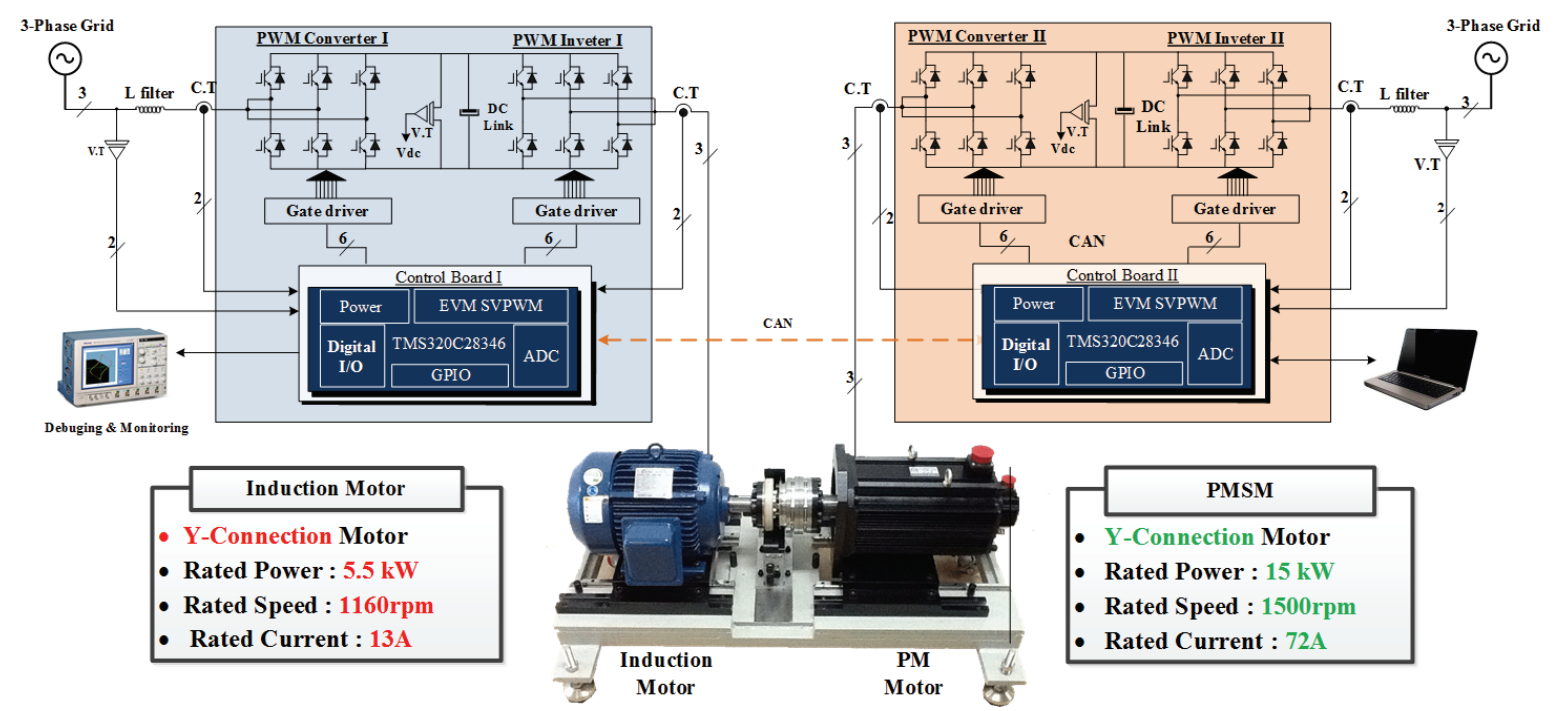

Fig. 8. Flow chart of the proposed field weakening control algorithm
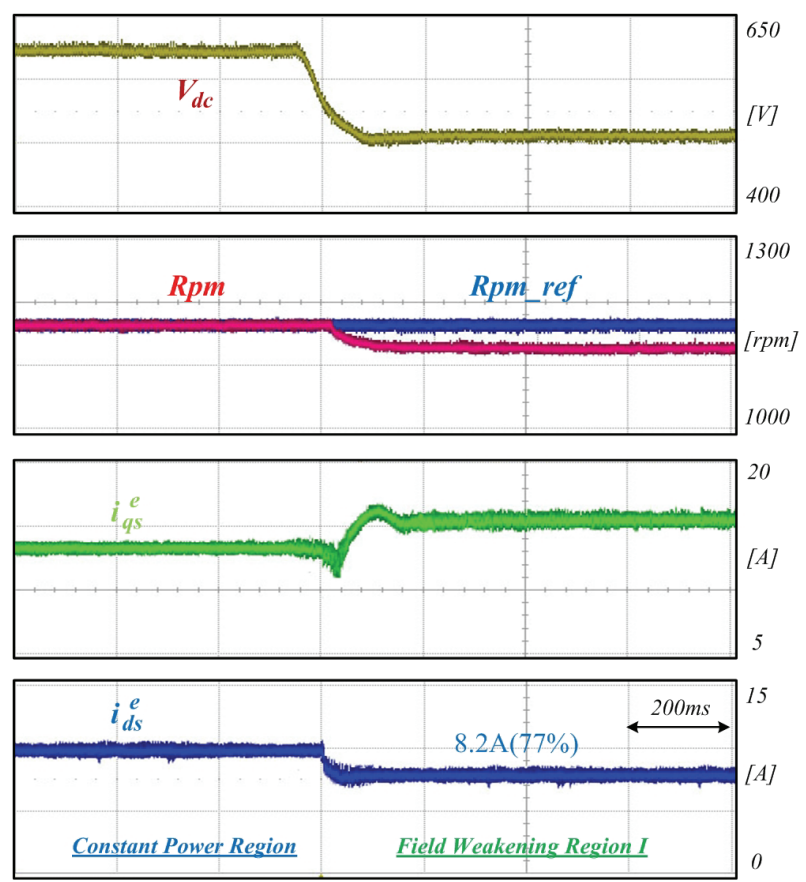

Fig. 9. Field weakening region I: The conventional field weakening method under rated phase current

Table 2. Experiment Conditions in the region I

\begin{tabular}{c|c}
\hline \multicolumn{2}{c}{ Experiment Conditions } \\
\hline DC-Link voltage & $600 \sim 450[\mathrm{Vdc}]$ \\
\hline Connection & Y-connection \\
\hline RPM reference & $1160[\mathrm{rpm}]$ \\
\hline Rated load Power & $5.5[\mathrm{~kW}]$ \\
\hline
\end{tabular}

under the speed reference because the output power is decreased by the change of operating point as described in Fig. 1. Fig. 10 presents the experimental result of the proposed method in the region $\mathrm{I}$. The $\mathrm{d}-\mathrm{q}$ axis currents reference is determined by Eqs. (10) and (11). As the DC
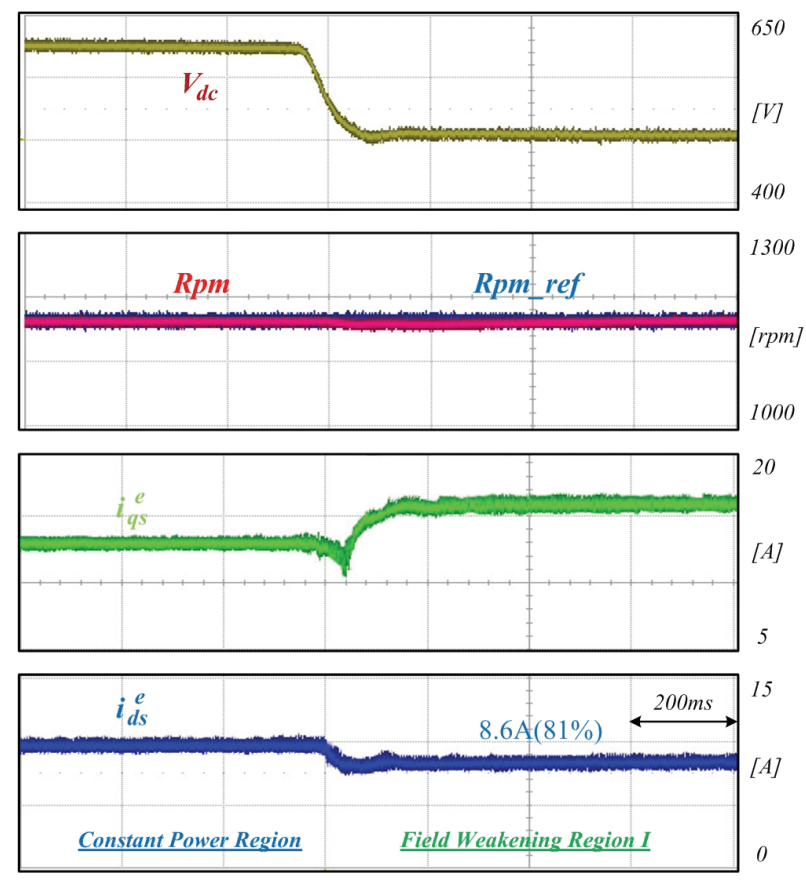

Fig. 10. Field weakening region I: The proposed field weakening method

voltage drops from $600[\mathrm{~V}]$ to $450[\mathrm{~V}]$, the q-axis current is increased and the d-axis current is deceased through the constant torque curve. So the operating point moves from the point $\mathrm{A}$ into the point $\mathrm{C}$ not the point $\mathrm{B}$ as described in Fig. 4. Finally, the motor can keep the rated rotor speed in spite of the DC input voltage reduction.

If the DC input voltage decreases more below about $450[\mathrm{~V}]$, the motor should be operated in the region II. In this situation, operating the motor at the rated output power is impossible. Therefore, the experimental condition is changed as shown in Table 3.

Fig. 11 shows the experimental result of conventional 
Table 3. Experiment Conditions in the region II

\begin{tabular}{c|c}
\hline \multicolumn{2}{c}{ Experiment Conditions } \\
\hline DC-Link voltage & $450 \sim 400[\mathrm{Vdc}]$ \\
\hline Connection & Y-connection \\
\hline rpm reference & $1160[\mathrm{rpm}]$ \\
\hline Rated load Power & $3.6[\mathrm{~kW}](60 \%)$ \\
\hline
\end{tabular}
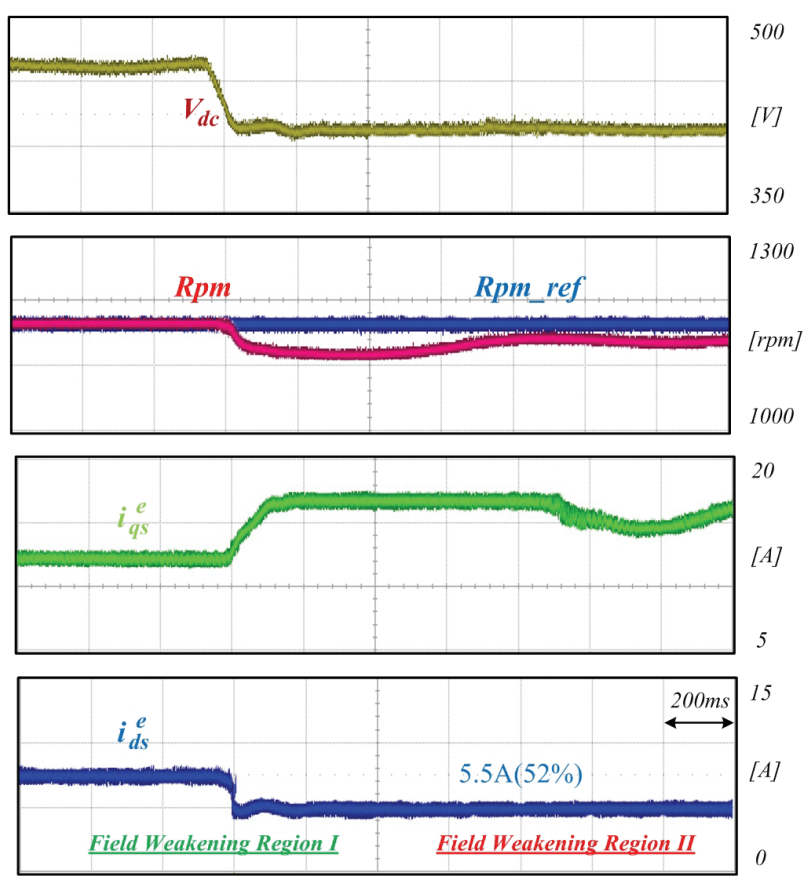

Fig.11 Field weakening region II: The conventional field weakening method under load $60 \%$
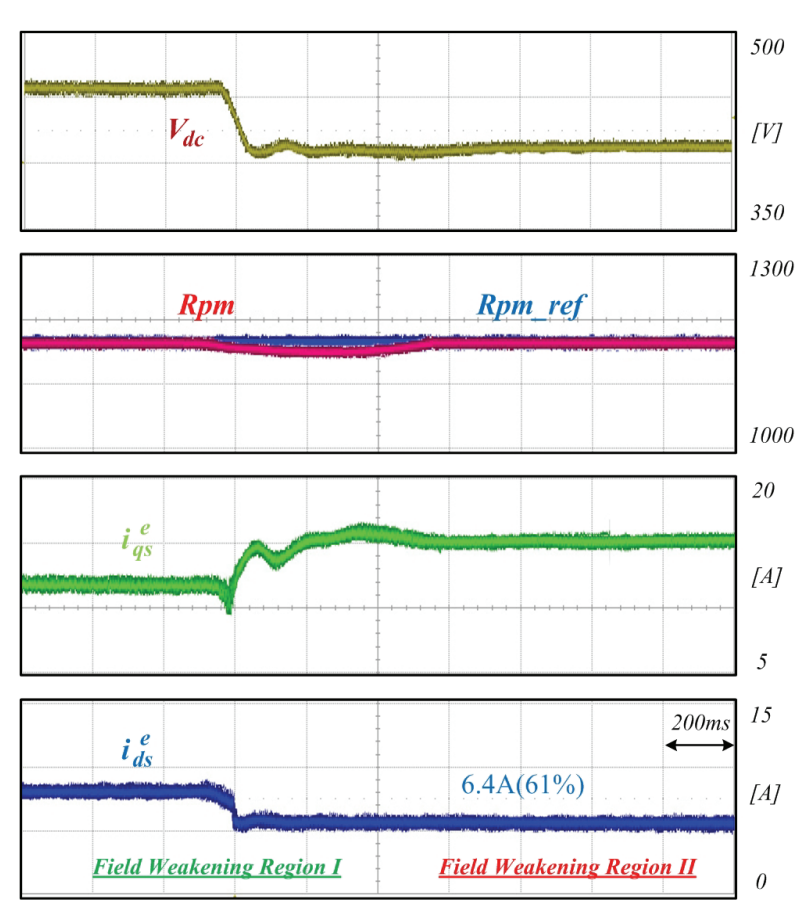

Fig.12 Field weakening region II: The proposed field weakening method under load $60 \%$ method in the region II of the field weakening control method. The DC input voltage is reduced from 450[V] to $400[\mathrm{~V}]$ and the load power is $60 \%$ of the maximum output power. As the DC voltage decreases, the output power and rotor speed decreases and the q-axis current is not controlled because the operating point is located outside of the voltage limit ellipse.

On the other hand, the proposed method can operate the motor with a fast response and a constant speed for the load power which is $60 \%$ of the maximum output power as shown in Fig. 12. The d-q axis currents are controlled through the maximum output power curve determined by Eqs. (15) and (16) considering the stator resistance. Therefore, the $d-q$ axis reference is located on the voltage ellipse.

\section{Conclusion}

This paper proposes an enhanced field weakening control method for the induction motor. The conventional field weakening method, which considers the current limitation, cannot keep the rotor speed at rated value when the DC-link voltage is changed and results in a long transient response time. However, the proposed method operates at rated power with the variable DC link voltage condition. In the region $\mathrm{I}$, the input $\mathrm{d}$-axis and q-axis currents were decided by the intersection of the voltage limit ellipse and the constant torque curve. This method can generate rated output power with the minimum phase current. In the region II, the operating point lies on the voltage limit ellipse that has maximum power in the given DC voltage level. This means that the motor operates at the maximum output torque in the given condition. Therefore, the proposed method can control the motor without rotor speed reduction. On the other hand, the proposed control method may cause the motor overheating by increasing the motor current above the rated value. So the temperature must be monitored to prevent the overheating when the proposed field weakening method is applied. The feasibility and effectiveness of the proposed field weakening method were verified through the experimental results.

\section{Acknowledgements}

This paper was supported by the New Professor Research Program of KOREATECH in 2016.

\section{References}

[1] Myoung-Ho Shin, Dong-seok Hyun, Soon-Bong Cho, "Maximum torque control of stator-fluxoriented induction machine drive in the fieldweakening region," IEEE Transactions on Industry 
Applications, vol.38, no. 7, pp. 117-122, 2002

[2] Xingyi $\mathrm{Xu}, \mathrm{D} . \mathrm{W}$. Novotny, "Selecting the Flux Reference for induction Machines in the Field Weakening Region," Industry Applications Society Annual Meeting, vol.1, pp. 361-367, 1991

[3] G. Gallegos-Lopez, F. S. Gunawan and J. E. Walters, "Current control of induction machines in the fieldweakened region," IEEE Transactions on Industry Applications, vol. 43, no. 4, pp. 981-989, 2007.

[4] A. Bünte, H. Grotstollen, P. Krafka, "Field weakening of induction motors in a very wide region with regard to parameter uncertainties," Proceedings of the IEEE Power Electronics Specialists Conference, Vol .1, pp. 944-950,1996

[5] Sang-Hoon Kim, Seung-Ki Sul, "Maximum torque control of and an induction machine in the field weakening region," IEEE Transactions on Industry Applications, vol. 31, no. 4, pp. 787-794, 1995.

[6] H. Abu-Rub and J. Holtz, "Rotor oriented nonlinear control system of induction motors operating at field weakening," Proceedings of the IEEE IECON, pp. 1085-1090, 2007

[7] M. Mengoni, L. Zarri, A. Tani, G. Serra, and D. Casadei, "A comparison of four robust control schemes for field-weakening operation of induction motors," IEEE Trans. Power Electron., vol. 27, no. 1, pp. 307-320, Jan. 2012.

[8] P. Y. Lin, Y. H. Lai, "Novel Voltage Trajectory Control for Field-Weakening Operation of induction motor," IEEE Transactions on Industry Applications, vol. 47, no. 1, pp. 122-127, 2011.

[9] Yung-Deug Son, Yong-Joo Seo, Jun-Hyung Jung, Jang-Mok Kim, "Advanced Field Weakening Control for Maximum Output Power Operation of Seawater Cooling Pump Induction Motor in a Limited Environment," TKPE, vol.18, no. 6, pp. 540-546, 2013

[10] Dr. Dušan Graovac, Marco Pürschel, "IGBT Power Losses Calculation Using the Data-Sheet Parameters," Infineon, Application Note, V1. 1, January 2009.

[11] Sang-Hoon Kim, "The Development of Calculation Algorithm of Power Loss for Inverter in BLDC Motor Drive with Switching Modes," The Institute of Industrial Technology Kangwon National University, Research Report the Institute of Industrial Technology, vol. 24, no. A, pp. 119-126, 2004

[12] H.C.j.de jong, "AC MOTOR DESIGN," Hemisphere Publishing, 1989

[13] D. Zinger, F. Profumo, T.A. Lipo, D.W. Novotny, “A direct field oriented controller for induction motor drives using tapped stator windings," Power Electronics Specialists Conference, vol. 2, pp. 855-861, 1988.
[14] H. W. van der Broeck, H. C. Skudelny, G. V. Stanke, "Analysis and realization of a pulsewidth modulator based on voltage space vectors," IEEE Transaction on Industry Applications, vol.24, pp. 142-150, 1988

[15] D. W Novotny and etc, "Vector Control and Dynamics of AC Drives," Oxford, 1996

[16] T. Ohtani, N. Takada, K. Tanaka, "Vector control of induction motor without shaft encoder," Industry Applications Society Annual Meeting, vol.1, pp. 500507, 1989

[17] S. Morimoto, M. Sanada and Y. Taketa, "Wide-Speed Operation of Interior Permanent Magnet Synchronous Motors with High-Performance Current Regulator," IEEE Transaction on Industry Applications, vol.30, no. 4, pp.920-926, 1994.

[18] Yung-Deug Son, Won-Sang Im, Han-Seok Park, Jang-Mok Kim, "Analysis and Compensation of Current Measurement Errors in a Doubly Fed Induction Generator," Journal of Electrical Engineering \& Technology, vol.9, no. 2, pp. 532-540, 2014

[19] Yuan Cheng, Alain Bouscayrol, Rochdi Trigui, Christophe Espanet, Shumei Cui, "Field Weakening Control of a PM Electric Variable Transmission for HEV," Journal of Electrical Engineering \& Technology, vol. 8, no. 5, pp. 958-1250, 2013

[20] Youn-Hyun Kim, Won-Kyu Kim, Sol Kim, "Maximum Power Control of IPMSM Considering Nonlinear Cross-Magnetization Effects," Journal of Electrical Engineering \& Technology, vol.7, no. 6, pp. 806-1033, 2012

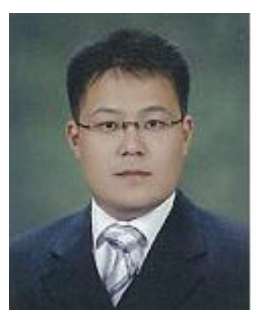

Yung-Deug Son He received the B.S. degrees in Control and Instrumentation Engineering from Korea Maritime University in 1997. He was a student researcher with Tokyo Institute of Technology, Japan, in 1998, and received the M.S. degrees in from Kobe University of Mercantile Ocean ElectroMechanical, Japan, in 2001, and Ph.D. degrees from the department of Electrical Engineering, from Pusan National University, Busan, Korea, in 2015, respectively. From 2001 to 2009, he was a Senior Research Engineer with Hyundai Heavy Industries Co., Ltd. He has been with the School of Mechanical Facility Control Engineering, Korea University of Technology and Education (KOREATECH), where he is currently an assistant professor. $\mathrm{He}$ is a Professional Engineer Building Electrical Facilities and a Professional Engineer Electric Application. His research interests include power conversion, electric machine drives, electrical facilities and renewable power system. 


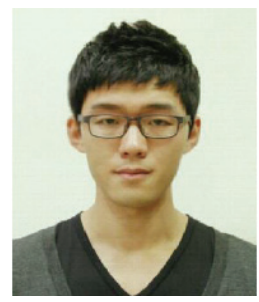

Jun-Hyung Jung He was born in Busan, Korea, in 1986. He received the B.S. and M.S. degrees in Electrical Engineering from Pusan National University, Busan, Korea, in 2012 and 2014, respectively. $\mathrm{He}$ is currently working toward the Ph.D. degree in the department of Electrical Engineering, Pusan National University. His research interests include power conversion, electric machine drives, multilevel converter.

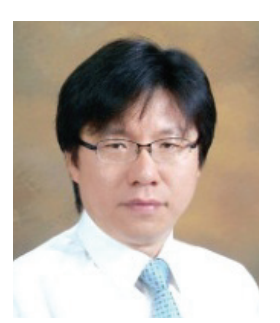

Jang-Mok Kim He received his B.S. from Pusan National University (PNU), Korea, in 1988, and the M.S. and Ph.D. degrees from the department of Electrical Engineering, Seoul National University, Seoul, Korea, in 1991 and 1996, respectively. From 1997 to 2000, he was a Senior Research Engineer with the Korea Electrical Power Research Institute (KEPRI). Since 2001, he has been with the School of Electrical Engineering, PNU, where he is currently a Research Member of the Research Institute of Computer Information and Communication, a Faculty Member, and a head of LG electronics Smart Control Center. As a Visiting Scholar, he joined the Center for Advanced Power Systems (CAPS), Florida State University, in 2007. His current interests include the control of electric machines, electric vehicle propulsion, and power quality. 